\title{
Volatility of workload on employee performance and significance of motivation: IT sector
}

\author{
Pooja Roy Dasgupta \\ Nagpur University, India \\ Email address: \\ poojasdasgupta@gmail.com
}

\section{To cite this article:}

Pooja Roy Dasgupta. Volatility of Workload on Employee Performance and Significance of Motivation: IT Sector, Science Journal of Business and Managemen.t Vol. 1, No. 1, 2013, pp. 1-7. doi: 10.11648/j.sjbm.20130101.11

\begin{abstract}
The average job in the IT industry is unskilled and is often not considered destination employment, but takes on a transient quality that accommodates the needs of the individual and will leave an employer to fill the same position again and again. Determining the reasons and factors why workers work has been the quest of industrial psychologists and management experts for years. It is generally agreed upon that if an employer can identify the reasons a worker is productive, reports to work on time, and remains with the company, the employer might then be able to apply these motivational factors unilaterally to the entire workforce. Applying this knowledge and fashioning the employment atmosphere to better accommodate the motivational factors of the employee, the employer becomes a more desirable employment destination, retaining employees longer, and increasing productivity and service at the same time. The wide range of, often conflicting, studies and theories in this area has led to a situation where no single model has been able to capture all the complexities of the internal and external influences on human motivation and performance. Models have broadly fallen into one of two categories: cognitive, focusing on the individual's thought processes and social-cognitive, focusing on the influences from social and contextual variables.
\end{abstract}

Keywords: IT Industry, Human Motivation and Performance, Motivational Factors

\section{Background}

For an organization to operate efficiently and effectively, it must know what its workload is. While there is no one exact definition of workload, it is commonly thought to be the amount of work assigned to, or expected to be completed by, a worker in a specified time period. Workload that is set too high or too low can negatively affect overall performance. The main objectives of assessing and predicting workload are to achieve an evenly distributed, manageable workload and to accurately determine the resource levels needed to carry out the work.

\section{Introduction}

Establishing and maintaining a stable work force in the IT industry is paramount to quality customer service and profit ability. Many workers in this industry are unskilled and do not consider the IT industry destination employment. A better understanding of employee motivation is one answer to this dilemma. A review of literature indicates that there is a link between the industry that person is employed in and work motivation.Research also shows that work motivation will vary between industries and will also change over time.

\section{Rationale}

The point of focus in the everyday changing scenario in the IT field today is to develop a work plan, for which we must have some realistic time estimates of what we can do within the time to be planned. Ultimately the question is, just how much time do we spend in our work cocoon anyways?

\section{What Is Workload}

Workload is the amount of work assigned to a worker in a specified time period.

We might not always have full control over total workload, but we CAN recognize its effects and take some action.

Everyone is different in their capabilities, and capability varies with task complexity, environmental factors, and 
personal behaviors (self awareness, confidence, etc.).

\subsection{What Is Workload Analysis}

Workload Analysis is a methodology to determine the time, effort and resources necessary to carry out the department's operations, resulting in identifying the organization's actual needs of human resources both in terms of quality and quantity, and develop these resources to achieve the goals and strategies that the organization wants to achieve in the various work sites. In this methodology, the workload is analyzed by evaluating the current human resources structure, and then the organization's actual needs of human resources are identified in order to implement the processes necessary to provide a particular service.

\subsection{Techniques of Workload Analysis}

Workload analysis techniques are series process to calculate the workload of a position / sub position, and also needs the number of people to fill the position / sub position. Workload analysis is very important to calculate exactly how many employees are needed to complete all of tasks in a section or department. In this method, there are three main stages which will be described below.

1. Determining the main output of a function / sub function and identify the sequence of work required to produce these outputs. For example in new product research department has three series of work activities to produce the output / outcome research, new product development. Namely: collecting data research, analyze data research and then prepared a report of research results and recommendations of new product development.

2. Breakdown chain of events into a more specific task force. For example in research data gathering activities are subdivided into more detailed activities, for example: data collection products of competitors, consumer behavior data collection, data collection needs of market, etc

3. Calculating the total amount of time required to complete a group task. For example how much total time needed to conduct research data collection; how long to do the analysis and how long to compile the results of research. From total number of hours to this activity could predict how the needs of the number of employees required for completing the entire task.

\subsection{Analytical Methods to Assess Workload}

There are two methods to assess workload:

Qualitative Factors

Quantitative Factors

\subsubsection{Qualitative Factors}

Qualitative factors are the ones that drive workload:

- These factors basically focus on Structural workload \& task demands

- Performance of essential tasks is taken into consideration while assessment of workload and is given high priority while deciding on the workload of any employee.

- There are other high drivers such as background of the employee and other needs of employees which are also considered while assessment of workload through this process.

\subsubsection{Quantitative Factors}

Quantitative factors are those factors which are based upon the quantity of work and the time required to accomplish the given task. Thus these factors mainly are, Time required vs. time available. Once this time has been estimated the workload can be assessed as:

- Low (less than 60\% structural workload)

- Medium (between 60-75\% structural workload)

- High (75-90\% structural workload)

- Extreme (greater than $90 \%$ structural workload)

\subsubsection{Prioritize}

* Prioritize and schedule tasks effectively. By understanding the priorities in our job, we can focus on important activities and minimize work on other tasks as much as possible.

* This helps us to get the greatest return from the work we do, and keep our workload under control.

\subsubsection{Delegate}

Delegation of tasks among employees, checks and corrects appropriately.

\subsubsection{Expand Available Time}

We can Use time available efficiently to complete tasks. We can Put off less important tasks until latter and break large tasks up into a series of smaller ones.

\subsubsection{Follow Procedures}

We can follow procedures appropriately and consistently.

\section{Workload Management}

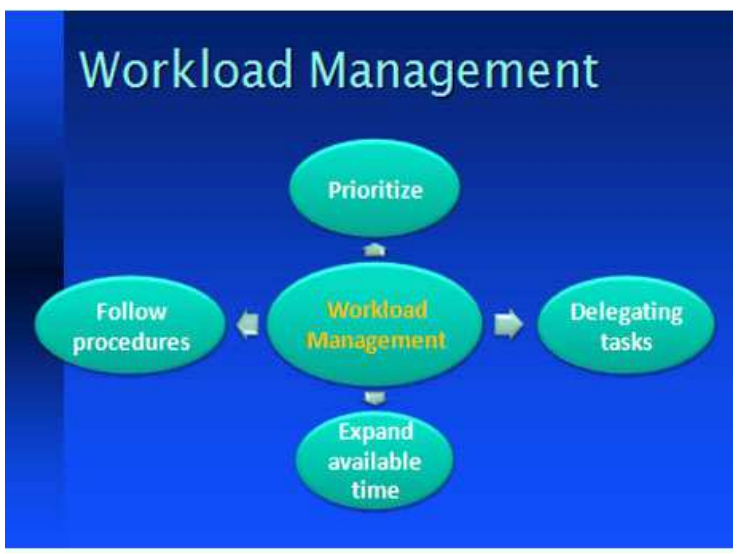

\subsection{Workload Management Goals}

Workload management:

- reduces the need for specialized, technical skills

- allows us to organize, manage, and monitor our 
workloads according to business goals

- allows business critical applications to receive the priority they deserve while other applications run as resources are available

- provides the necessary resource usage information to plan for changes in business workloads

- makes system more adaptive and responsive to changing environments

\subsection{Catalysts and Motivating Factors}

Some States set out specifically to reduce caseloads and workloads; others have reforms imposed on them; and still others arrive at workload reduction as an unintended effect of other initiatives. The impetus for workload reduction efforts typically emerges from one or more of the following catalysts:

- Following of law and order

- Employee retention

- Staffing

- Economical reasons

Effective workload management systems are an essential tool for organizations to:

1. Map staffing capacity against resources and demand

2. Provide robust evidence to enable monitoring, negotiating and accessing resources

3. Support a referral and escalation procedure through to service directors, elected members/board members/trustees when workload demands exceed staff capacity

4. Fulfil duty of care and contractual obligations to individual social workers workload management often appear as key ingredients in an organisation's comprehensive strategy to produce better outcomes for employees.

\section{Causes of Poor Workload Management}

- Failure to plan and rehearse

- Emergencies, equipment failures, and unexpected events

- Mission complexity

- Work area design

- Lack of department rest and endurance

\subsection{Identifying Areas for Improvement}

One of the key objectives in an employee performance evaluation is to address any of the areas that are most closely related to the employee's ability to reach his or her personal goals and contribute to the team. One may discuss the causes of any problems achieving goals, work together on proposed resolutions and emphasize problem solving and concentrating on future actions. The employee evaluation should be focused on the key success topics to avoid potential negative feelings and defensive reactions. If any of the obstacles relate to a skill gap, one can provide a skill development or training plan or identify additional resources available for the employee to overcome the difficulties and become more successful.

\section{What is a Performance Standard}

Performance standards are management-approved expressions of the performance threshold(s), requirement(s), or expectation(s) that employees must meet to be appraised at particular levels of performance. Each critical element must have a Fully Successful or equivalent standard established. Technically, neither non-critical elements nor additional performance elements require a Fully Successful or equivalent standard. However, to help employees and work units understand the expectations for performance on these elements, we recommend that they have a clear idea of what is considered fully successful performance.

\section{How to Monitor Performance}

Monitoring performance means measuring performance and providing feedback to employees. Agency appraisal programs are required to provide ongoing appraisal, which includes, but is not limited to, conducting one or more progress reviews during each appraisal period. In addition to a once- or twice-a-year progress review, which is sometimes a formal part of the appraisal process, supervisors and employees should discuss performance informally and often.Determining how to monitor performance is an important step in developing performance plans.

\section{Recognizing Employee Performance}

Another aspect of employee performance and business success is employee recognition. Annual employee appraisals aren't enough--employees appreciate frequent and regular feedback. When the management team provides regular feedback, it motivates employees to maintain consistently good performance. Inc. magazine's article "Employee Reward and Recognition Systems" notes that, "By rewarding and recognizing outstanding performance, entrepreneurs will have an edge in a competitive corporate climate." Having that edge strengthens your position in the industry and brings you closer to your business objective, which is greater profitability.

\section{Principles for Performance Management}

* View performance measurement as a valuable tool, not as an evil

* Acceptance of the performance measurement process is essential to

* Measure what is important-not what is easy to measure

* Develop employee performance plans that are flexible 
enough to allow for changes in program goals to keep the process credible

* Rely on multiple measures

* Employees should perceive that performance measurement is important

* Management should demonstrate that performance is critical to organizational and individual success

\section{Feedback}

Effective and timely feedback addressing employee performance on elements and standards is an essential component of a successful performance management program. People need to know in a timely manner how they are doing, what is working, and what is not working. Feedback can come from many different sources: managers and supervisors, measurement systems, peers, and customers, just to name a few. Using multiple sources of feedback, which is sometimes called 360-degree assessment or multirater appraisal, is done in a variety of ways, but most methods are computerized and the raters are anonymous. Whether we need or want to use multirater appraisal depends on what you want to measure.

\section{Employee Motivation}

Employee motivation has been studied at length.Through research, a significant myth has been dispelled and shown to be incorrect.The biggest misconception was that good wages were always the primary motivational factor among employees regardless of the industry by which they are employed.This generalization, or supposed knowledge, has misdirected front line supervisors of industrial workers for years. The result has been misunderstood industrial employees who were more concerned with other motivational factors that their supervisors perceived as secondary or were not aware that existed. It is time the human resource process of hiring, training, and retaining employees takes a step up to the next level.The paradigm has shifted and the IT industry must make the necessary accommodations to insure a high level of service to guests in order to remain competitive. There are new strategies to implement and the companies that reinvent the hiring process, providing superior customer service, are the organizations that will lead the service industry, but all of these strategies involve an increased understanding of employee behavior and their motivation.

\subsection{Definition of Motivation}

Just like any other word, there are variations of definitions to describe a concept. Motivation too has many different definitions, but it is important to focus on those that are related to the workplace. Understanding exactly what motivation is will help managers decide what actions to take to encourage their employees. The definition of motivation starts with the root word, motive. Webster's
Dictionary defines motive as, something that causes a person to act. Therefore, motivation can be defined as, the act of providing motive that causes someone to act (Shanks, 24). In other words, according to Nancy Shanks, motivation causes someone to act and someone else cannot make someone motivated. It is the discretion of the person to decide if they are going to be motivated or not. Motivated and unmotivated are not opposites, but instead, there are determining factors that could cause someone to be unmotivated, such as life events and attitudes towards a specific job. With relation to the workplace, Ray Williams, who writes for Psychology Today, defines motivation as, "predisposition to behave in a purposeful manner to achieve specific, unmet needs and the will to achieve, and the inner force that drives individuals to accomplish personal organizational goals" (Williams). A person becomes motivated in order to achieve their own personal goals as well as the organizational goals. The more motivated an employee is, the more likely they are to have organizational commitment and identify themselves with the organization. This will meet some of the unmet needs, and connect them with the organization. If willing, the manager is able to give the employee incentives to meet their own goals and the goals set by the organization. Richard Ryan and Edward Deci, from the University of Rochester, agree that motivated means that the person is moved to do a particular act (Ryan and Edward, 54). The authors describe motivation as, the "orientation of motivation concerns the underlying attitudes and goals that give rise to action" (Ryan and Edward, 54). Although the words of the definitions might be different, they all are describing the same concepts. Motivation is the act of getting someone to act on a situation.

\subsection{About Motivation}

Companies and organizations everywhere need employees to work with. However, while getting employees can easily be done through the recruitment process, there is the more difficult task of keeping them motivated to work hard to achieve improved performance and to attain both organizational and personal goals. Shanks (2007:25) notes that managers erroneously 'often assume that employees are motivated or will respond to inducements from managers' without realizing that not all employees will be motivated. More so, she asserts that in reality majority of employees are "motivated by any number of factors, while others may not share that same drive or high level of motivation' (Shanks 2007:25). This situation calls for managers to have a clear understanding of the human being. D'Ausilio (2008) however suggests that most managers are either too busy or don't take the time to understand the concept of motivation and therefore fail in their quest to effectively motivate their workers.

Various studies have been done to see the effect of the use of rewards as motivation for employee performance. While some of the studies indicate that the use of rewards as motivation enhances employee performance, others note 
that rewards do not motivate. In a recent study by Veling and Arts, the authors aimed at examining "whether monetary rewards can reduce failures to act on cued task goal' (2010:188). With a research sample comprising of thirty-six (36) undergraduates, the authors experimented to see how quick their respondents reacted to specific tasks when given a range of monetary rewards ranging from low to high rewards. The studies found out that giving relatively high monetary rewards, led to 'overall faster responses' to the specific tasks given to respondents. The authors noted that respondents overall fast response to task was positively correlated to the high rewards given them.Conversely, the authors also noted that when rewards were on the low side, respondents either slacked or showed little in the task at hand. Their finding is consistent with other studies which noted that relatively high monetary rewards may function as a catalyst for enhanced effort or determination by employees to perform well (Bijleveld et al. 2009, Locke and Braver 2008, Waugh and Gotlib 2008).

\subsection{Sources of Motivation}

Motivation is the driving force that comes within an individual to satisfy his/her unsatisfied needs. Needs and expectations are drivers that motivate an individual to achieve those needs. These motivators are often considered in terms of being internal or external. According to Mac and Sockel (2001), the internal motivators are related with intrinsic needs that satisfies an individual while external motivators are environmental factors brought up to individual by organisation. intrinsic motivation makes a person to be productive as it comes within him/her while extrinsic motivation results once the unmet needs have been achieved(Marquis and Huston, 2008). A person is intrinsically motivated when he/she engages in the activity that gives pleasure and satisfaction (Deci and Ryan, 2004). On the contrary, Deci and Ryan (2004) explained extrinsic motivation as an external control over a person who gets engaged in the activity, not for pleasure or satisfaction but for attaining a positive outcome or avoiding a negative outcome.

Hence, a manager should strive to stimulate an employee's intrinsic motives to complete a task given. Intrinsic motives can be satisfied by the work itself. Since the task given to an individual provides interest, challenges and opportunities for personal growth and development, it has been considered as the main source of motivation (Molander, 1996).

\subsection{Ways of Motivating Employee to Ensure Better Performance}

The employees' experiences at work show their feeling towards their jobs either positively or negatively. Employee motivation is taken into account by every organisation as one of the major challenging tasks. Motivation can be classified as positive or negative. The managers should encourage positive motivation to enhance performance. On the contrary, when the performance is demotivating, the approach adopted would be determined by persisting situation.

\subsubsection{Communication}

Communication is always an effective way to improve motivation and enhance productivity. There should be twoway communication between managers and staff that generate feedbacks on the performance.

\subsubsection{Job Participation Scheme}

Participation scheme enables staff to become a member of decision making team and express their views on organisational decisions. This leads staff to be responsible to increase their efficiency and productivity at work.

\subsubsection{Fringe Benefit}

If an organization can retain the employees by providing them with the fringe benefit. This prevents turnover if effectively use and increase the productivity.

\subsection{Demotivators}

Every bit as important as identifying what an employee wants is knowing what employees don't want.Avoiding demotivators is another key to staff retention.Different aspects of the job will attract different employees, but demotivators will be around long after an employee has chosen a job.(Spitzer, 1995)These obstacles to blissful employment can take on a number of forms.Politics and unclear expectations are two problems that organizations face.Other problems that have a negative effect are constant change, low quality standards, and unproductive meetings. The first step to eliminating these moral busters is to obtain employee feedback to identify consistent themes. Employees tend to appreciate these collaborative efforts as they are viewed as tangible efforts to improve the quality of the work environment.Employers who assume that they know what the problems are relying on their own perspective and fail to see the issue through the eyes of their employees. The work environment has undergone considerable changes over the past years in terms of the nature and scope of work. The changing nature of the work environment has necessitated different ways of management approaches.Yet an important and constant factor has been the ways in which managers motivate their workers to help achieve not only the organizational goals but also that of their own personal ones. This difficulty stems from both the complex nature of the work environment as well as the wide array of people employed within them.Human beings are by nature not homogeneous entity. They have a variety of needs, aspirations, as well as differing perceptions of what constitute appropriate rewards for effective motivation. Thus motivating workers requires an in-depth understanding of the human nature,individual differences and perceptions of appropriate rewards and incentives, as well as a combination of extrinsic and intrinsic rewards. Unfortunately most managers tend to believe, rather erroneously that they can adequately 
motivate their workers by offering rewards such as higher pay, bonuses, and paid vacations.Morse (2003) notes that, in most cases there exist an 'extrinsic incentive bias' which is perpetuated by both managers and employees. As noted by Atchison (2003), this bias does not stem from reality but are rather rooted in myths surrounding employee satisfaction. Research has however shown that such monetary incentives do not motivate workers and may in certain circumstances become demotivators. Shanks (2007:32) asserts that monetary reward 'motivates only to a point; that is, when compensation isn't high enough or is considered to be inequitable, it's a demotivator'.

\section{Recent Trends in IT}

The current world is techno- centric more than ever. The rapidly expanding information sector has left a huge disparity between where the world is heading and the approaches businesses are employing to run their operations. The challenges to businesses are therefore phenomenal especially considering the fact the IT industry is undergoing a tectonic shift in technology. Different aspects of the computing landscape are changing at the same time including communication, delivery platforms and collaboration channels. With the information technology sector, technological innovations are shortlived as they are frequently changing with time. Nothing lasts forever.

\subsection{Social Media}

The world is increasingly using social networking sites to stay in touch and communicate. The focus of enterprise marketing has now shifted to the use of social media for promotion of products and services. Organizations are now becoming social enterprises. Social media has provided a platform for business to directly access a global audience. Businesses are employing social media marketing due to its affordability compared to traditional marketing strategies. Social network is quickly shaping the direction of society and business.

\subsection{Resource Management}

Servers are being virtualized which benefits businesses in reducing work load management. Data centers are moving towards smaller sizes but with greater density for data storage, i.e. creation of infinite data centers. Virtualization enables the improvement of vertically scale data centers. Its use optimizes server performance hence creating more floor space and saving on energy.

\section{Limitations of the Research}

Motivation is a concept with a broad area of research. It contains a wide range of theories on factors that motivate people (content theories) along with theories that describe how behaviours are initiated, directed and endured (process theories). The research work focuses only content theories which identify the particular needs that drive the human behaviour to perform better or worse.

The research has tried to present the impact of motivation and job satisfaction on employees' mental health, social life, and family life in order to show the significance and scope of the research topic. However, they are only considered in the theory but not clearly shown on the observed part of the research.

\section{Conclusion}

Aristotle says that every action that someone takes is due to one of seven causes that he identified (Aristotle). These causes include: chance, nature, compulsions, habit, reasoning, anger, or appetite ("Aristotle's Seven Causes"). Managers should take the time to understand why their employees are performing the way that they are. First, a manager should be a leader. Understanding human behavior in workplace has been one of the most prioritized tasks for any organization. This is due to major changes like globalization and technological advancement that change in the structure of the business done, the workforce behavior and management of employees. To keep up the business state of the art and become successful, the organizations should acclimatize with these changes (Vercueil, 2001). So, it has become important for employers to know what motivates their employees rather than emphasizing them to increase productivity. When written effectively, employee performance evaluations are very helpful to the productivity of an organization. They provide with the tools to gather information and communicate company and individual goals to all employees. They also provide a structure for a pay-forperformance system that rewards employees for successfully achieving those goals. These evaluations are tools that have the ability to make everyone more productive and engaged in their jobs and therefore make the company more successful.

\section{Suggestion for Future Researchers}

Motivation is a continual process. Therefore, it needs to be continued and developed as individual and organizational factors change over time. It may be of interest to have a constant view of what motivates the employees and provides them with satisfaction. Also, it may be attractive to compare the received results with similar surveys done in the similar banks or other organization. An evaluation of the surveys may provide the bank with useful information about the success/failure of changes regarding the work and the development in the job satisfaction of the employees. 


\section{References}

[1] "The Effects of Public Service Motivation on Job Choice Decisions: Disentangling the Contributions of PersonOrganisation Fit and Person Job Fit”. Robert K.Christensen and Bradley E. Wright (2011)

[2] "The Role of Motivation for Treatment Success". Alice Medalia (2011)

[3] "Intrinsic Motivation at Work". Kenneth W. Thomas (2012)

[4] "Essential Writings on Management". Peter Drucker (2009)Website:http://safaribooksonline.comhttp://citehr.com 